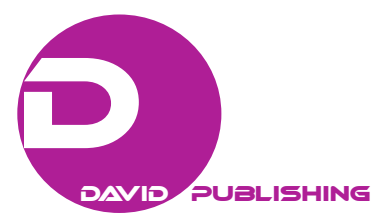

\title{
The Free-Flowing Voice and its Connection With the Mother Tongue
}

\author{
Ann Mary Ruth MNZM \\ Whitireia, Wellington, New Zealand
}

\begin{abstract}
Does the native tongue confer greater authenticity and connection? And how does this connect with languages acquired later in life? From thirty years of directing, training, and auditioning actors from a range of ethnicities, I have believed that the mother-tongue has a particular and organic connection for an actor, one difficult to achieve in any other language. This belief was confounded in a laboratory conducted with Romanian actors, March 2013. The work was performed in both English and Romanian and it was with a sense of shock that I observed that the work was more vital, compelling, and physically and vocally engaged when they spoke in English. What were the factors at play here and what are the implications for future work? Patsy Rodenburghas written of the giddy delight children find in language. Under what conditions does the native tongue evoke that "giddy delight" and where and when does it become an obstacle to such pleasure?
\end{abstract}

Keywords: Tikanga Māori, viewpoints, mother-tongue

\section{Performance Research Into Immediacy and the Mother-Tongue}

Sometimes there is a moment within a creative research project where previous assumptions are challenged and beliefs confounded, a moment when a whole new set of questions arise. This is inevitably a moment of deep engagement. It is a place of checking and re-balancing. Questions and the condition of not knowing bring life to the work, they jolt us awake, our creative and intellectual juices increase their flow, and in the light of this questioning, everything that went before has to be reviewed and re-examined. They take us to a place of new possibilities. Bogart (2013) writes "Each worthwhile project is animated by curiosity, by questions, by a nagging itch that requires attention". In 2013, the author began a performance laboratory in Bucharest with one set of questions and in the midst of the work, confounded by unexpected results, was led into a raft of new questions, a nagging itch that has remained with me, making the laboratory a significant and fertile milestone in my creative journeys.

\section{A series of Performance Laboratories}

From 2012-2014 the author had conducted a series of performance-as-research laboratories using extracts from Gregory's (2006) poetic text, Bone Songs and juxtaposing this with improvised, biographical text generated by the actors themselves. The laboratories took place in London, Bucharest, and Shanghai and in all cases the majority of the participants did not speak English as their mother tongue, though this was the working language for the workshops. The focus for each of these laboratories varied, but in each case the "conversation"

Ann Mary Ruth MNZM, Ph.D., Department of Arts, Whitireia. 
between mother tongue and English, written text and personal biography was central to the exploration. The work was explored through frameworks based on the indigenous rituals of the Māori ${ }^{1}$, which have long been integral to my working process, and through the Viewpoints acting methodology ${ }^{2}$, an approach developed by the American director, Anne Bogart.

These laboratories were part of an on-going research into creating work that is artistically structured or fixed, and simultaneously created within the moment, the intention being to combine artistry and improvisation. The challenge is to wake ourselves up, to see anew, to respond out of the moment: not out of memory (reaching into the past) nor out of desire (reaching into the future), both of which produce what Peter Brook has famously described as "deadly" theatre (Brook, 1968, p. 12), ${ }^{3}$ which is experienced all too often in our theatres. I employed Māori frameworks and Viewpoints because together their processes anchor actors to the present moment. They refocus performers' attention towards purpose rather than performance, towards the outer, rather than the inner world. They favour connection both to each other and to audiences, and the kind of alertness more often seen in sporting events.

\section{Bone Songs}

Bone Songs is an exploration into our humanity through an imagined conversation with one man's past selves. In this way it speaks to all of us. Peter Brook describes the work as "unique"- there's no other word that can contain this remarkable work. Each phrase is a painting, a poem, an act of theatre, and an autobiography. André leads us through the ice floes of memory, where depths of pain melt into a sea of compassion ${ }^{4}$. Bone Songs is Gregory's exploration of his marriage, the words that are left unspoken, the influence of childhood experiences that limit ability to relate. It is told in a series of poems set in Antarctica, each of which have highly evocative titles such as Arctic Love Song 1 and Waking the spiders on the floor. This is not the literal landscape of the ice but an Antarctica of his mind, one where polar bears perhaps roam and where his young and middle aged selves can meet and talk and explore the joys, challenges and dangers of love. This makes it an ideal text with which to juxtapose personal biography, Gregory's words resonating with the cast's own life experiences, leading them to reflect on them in ways that can be both profound and quotidian.

At the same time its highly poetic nature created a strong tonal contrast with personal anecdotes. I wanted to explore how these different registers might connect and bring life to the performance, much as the mixture of grief and laughter so often brings an intensity of life to encounters on the marae ${ }^{5}$. Speakers during a pōwhiri ${ }^{6}$ move freely from teasing the living to mourning the dead: "The mixture of grief and happiness seems strange to outsiders, but not on the marae... On the marae life is all of a piece, and there is no attempt to enforce one type

\footnotetext{
1 The indigenous people of New Zealand.

${ }^{2}$ Viewpoints are, in the first instance, a language for discussing what occurs on stage, a language that is not based on psychological relationships between "characters" nor on narrative nor text. They are, rather, a language based on the physiological, born out of acute observation of each present moment. In this way the viewpoints articulate a tangible reality, something that exists in the world to which the actor pays attention. Scott Cummings describes them as "a system of fluid and variable signs, which in staging a performance are arranged and combined for aesthetic or rhetorical purposes" (Cummings, 2006, p. 113). The nine viewpoints are: Spatial Relationship, Shape, Relationship to Architecture, Tempo, Duration, Kinaesthetic Response, Topography, Gesture and Repetition.

3 Brook coined the term in the 1960 's, claiming that: "as a whole, theatre not only fails to elevate or instruct, it hardly even entertains".

${ }^{4}$ Brook, Peter. Quoted on the cover of André Gregory's Bone Songs 2006.

5 The formal space outside the meeting house of a Māori tribe where formal meetings take place, often also used to include the complex of buildings around it Māori tribal meeting place.

${ }^{6}$ Welcome Ceremony.
} 
of emotion or another". ${ }^{7}$ Gregory's text invites a similar range and as progressing through these laboratories the casts grew ever more open in revealing intimate stories from their lives and allowing them to resonate against the work of the group and the Gregory text (see Figure 1).

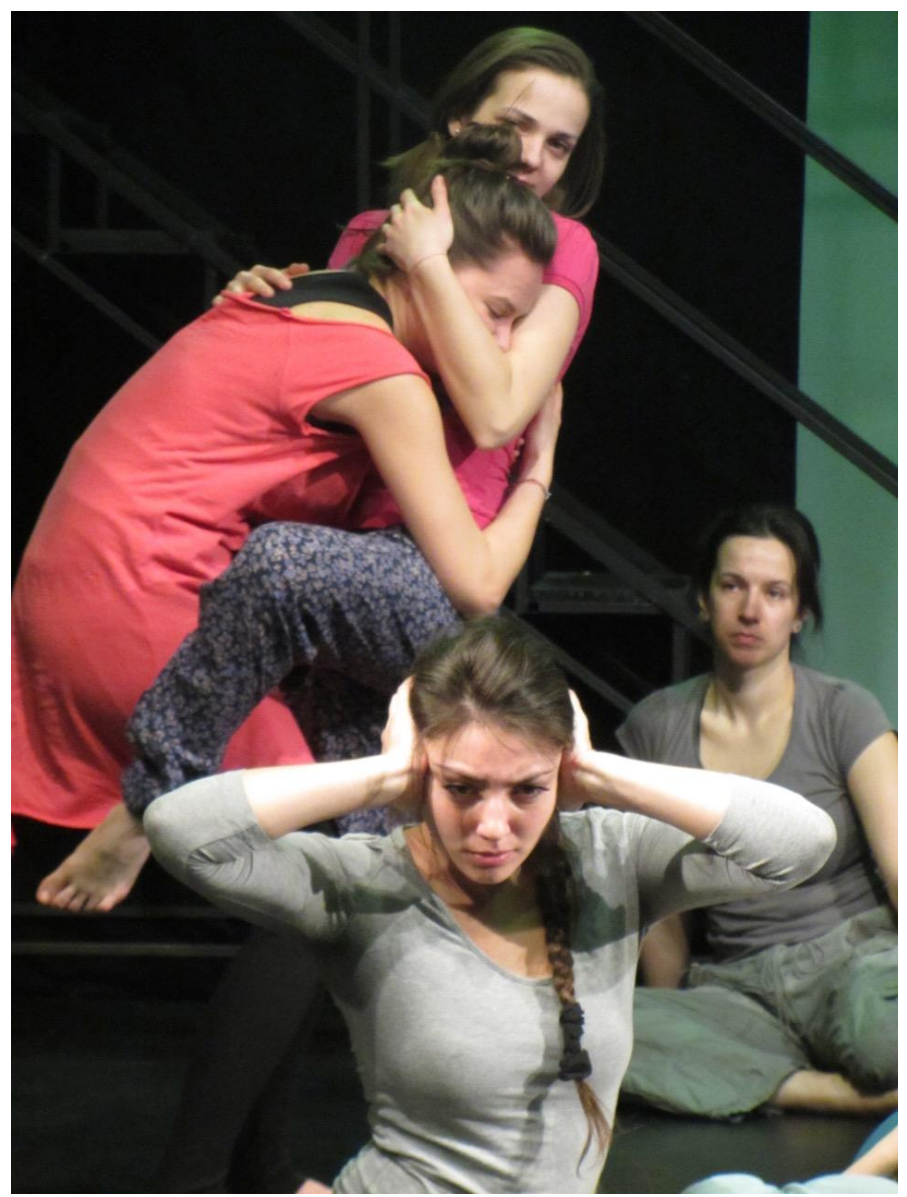

Figure 1. Actors working sequence Bucharest, 2013.

\section{Utilising Tikanga Māori Ritual Frameworks to Hold the Work}

In each of these laboratories the work was introduced by establishing rituals to begin and complete each session, bringing in the individual lives and ambitions of the actors, setting a principle that would continue throughout the workshop of intertwining the personal and the professional. The participants were not asked to leave their personal lives outside the rehearsal room, but rather to allow everything that affected them to be a part of the work. This process is based on tikanga Māori ${ }^{8}$ rituals and is one that I use to support all my work. As actor and teacher Teina Moetara comments, speaking of rituals on the marae:

You never lose who you are - in fact you acknowledge it, clock it, and everybody does that... You understand that all the threads that make up you as a person are there-you don't have to leave a part of you at the door. In fact your main task is to continue to pull all these threads in. ${ }^{9}$

In the case of this laboratory I was also setting up a practice of sharing personal stories, which would then

\footnotetext{
7 Salmond Anne. Hui: A Study of Māori Ceremonial Gatherings, Auckland: Reed. 1975, p. 112.

8 Rituals and customs. Everything organised according to Māori custom.

${ }^{9}$ Moetara, Teina. Interview with Annie Ruth, 3 December, 2009.
} 
become a part of the performance text. In introducing them in this context I was generating a sense of ease in story-telling, hoping that the actors would retain a similar simplicity and directness in encountering their audience. The Romanian acting teacher, Tania Filip saw this as a unifying force within the Bucharest workshop, one that was apparent in the final presentation: "And, of course, the presence of Māori culture through the Māori rituals shown and performed at the beginning of each work session, gave the expected unicity of this workshop" (Filip, 2013).

\section{Viewpoints and the Outward Gaze}

Both tikanga and Viewpoints-based choreography require the actor to constantly "read the room" and adjust their response to that reading, sometimes in small, subtle ways, sometimes in major realignments. They set up a situation in which every movement brings out a response, even when the movement is not fully understood. This means the space remains kinaesthetically alive and filled with "unknowingness" with all the danger that implies. They were being asked to focus on the physical life of the body in a series of choreographic tableaux created in parallel to the text, and to put all their attention on the timing of these chosen physical stances against the movement of their fellow actors. This movement choreography, based on the principles of Viewpoints improvisations, is a flexible tool for generating work that is poised between the artistically fixed and the unpredictably free. The task was to generate the sense of danger and excitement that arises where the future is genuinely unknown.

\section{Viewpoints-based Choreography}

To clarify this by an example: the play text of a conversation between a dying woman and her husband in Bone Songs might be juxtaposed with a seven-step movement sequence based on an image such as a Rodin sculpture or a theme of oppression and release. When the text is draped over the independently created action, a dialogue between act and word ensues with neither subservient to the other. Eelke Lampe speaks of the effect of this kind of dissociation of elements as creating a clash out of which new life emerges:

she [Bogart] dissociates movement from verbal text, live music from recorded, visual elements and sound production from the expressive behaviour of the performers. The resulting clash allows for a new creative merge of the disparate elements in the spectator's mind during the performance experience. (Lampe, 1992, pp. 25-6)

Rafael (2008) describes them as "a physical architecture of performance that can enhance or contrast with the relationships and words of a text" (p. 144). The layering leads to unexpected juxtapositions of image and sound, enabling a fresh perception of the world. The very disjunction can help us to see anew. The words are the final act in the struggle to overcome the difficulty of reaching across all our separate lives and genuinely communicating our shared humanity. They are not the sole driver of the act. The actor's task of holding all these elements in awareness is huge. But its very difficulty stimulates her to reach out towards the challenge. The demand is that they stay in that state of impossible effort and work from that place.

Thus, the actors were combining Gregory's poetic text, biographical stories, and a set choreography, all running on separate tracks, so that the spoken text and the choreography did not always coincide in repeatable sequences. Sometimes the choreography might progress very quickly, the actors picking up the tempo as they passed the energy between them, while the spoken text moved slowly and delicately. Sometimes the movement paused while the text continued. Word and gesture were not fixed to each other but occurred in unpredictable combinations. And all had to be timed against the movements of the other actors within the seven-step 
choreography, forcing them to watch each other fiercely (see Figure 2).

The "rules" of this choreographic challenge were that no actor could ever be more than one step apart from the other actors within the movement sequence. For example, the section of the Gregory text titled, Arctic Love Song $l$ was divided into three rhythms, the titles of which were: Looking or Imagining?, A Honeyed Meeting, and Catch a Falling Star. Each series of stills incorporated an awareness of Viewpoints principles, playfully revealing something about the work/performance space. I then asked the actors to move from one position to the next, exploring different qualities and tempi in response to each other, making sure that the sequencing of the "stills" remained synchronised. We then draped the text over the action created out of the sequence of stills and their ever-changing movement linkage. The struggle for the actors was to allow this separation of text and movement to continue, to not fall back into a mind-set where "this gesture belongs to this word" but rather to allow themselves to be surprised and affected by ever-changing combinations. Often they struggled to keep their individual choreography linked to the group. Lapses of attention led to an individual following their own sequence without regard to the overall group with the result that the work lost its organic life and habit took control. The actor was no longer present within the work but delivering a formulaic rendition, drifting into memory and the knife-edge of the present moment was lost. The actors recognized this challenge and worked with each other to retain the "game" of the timing, and, for much of the time, they succeeded.

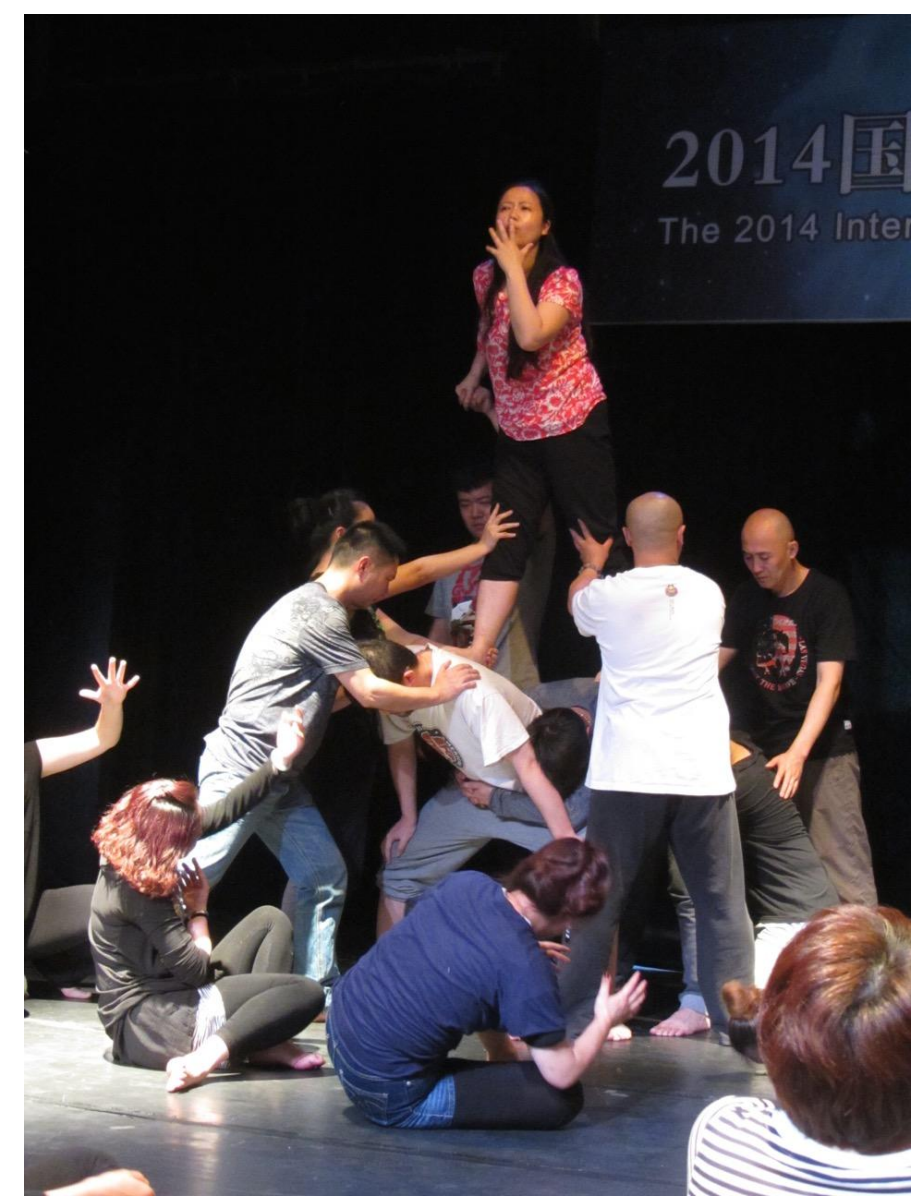

Figure 2. Actors timing their choreography against each other, Shanghai, 2014. 


\section{Confounding Expectations}

The aim in this work is the engendering of a sense of exceptional life and vitality, not only through a particular actor's outstanding ability or through the coalescence of factors in a unique and miraculous moment of presence where "the uncanny, the magical and the dangerous hover at the outer edges of these limits [what is known and knowable]" (Goodall, 2008, p. 18) but through the application of structures that direct the actor's attention towards an intense reading and responding to the shifting sands of the present, allowing artistic, fixed structures and improvisation to co-exist. The presence sought lies in the interaction, the space between the actors, not in a particular individual. Both tikanga Māori and Viewpoints encourage such an approach, and I saw this at work in the performances of the actors in Bucharest. Bogart writes: "While paying attention to the details and welcoming insecurity, while walking the tightrope between control and chaos and using accident, while allowing yourself to go off balance ... something is bound to happen” (Bogart, 2001, p. 136). And in all three of these laboratories, happen it did, supported by these frameworks directing the actors' gaze outwards and through their willingness to engage with this, for them, alien approach.

\section{The Bucharest Laboratory}

In Bucharest ${ }^{10}$ the laboratory was working with MA actors, most of whom already had substantial professional careers. I had made the decision to work in both Romanian and English, believing that the connection with both the received and self-generated texts would be greater in the actors' native tongue. I was testing the mix of received and improvised text within the Romanian context. I had introduced speaking both personal and received text in Romanian as well as English. And it was here that the outcomes became surprising, challenging my previously held beliefs. In the past I had worked in many multiple-lingual situations and noted the aliveness and sincerity that the mother tongue brought with it. In New Delhi, India, February to March 2012, I had directed a group of 19 actors, all speaking the given text in Hindi, though for only a handful was Hindi their first language, there being were 14 different mother tongues within the cast. When I got the young woman playing a soldier to speak in her native Tamil the speech took on a depth and urgency missing in the Hindi. I expected a similar, galvanising effect among the Romanian actors when they brought their own language into play. But to our collective astonishment, the effect was the opposite, observed not only by myself, but commented on by the cast and their acting teachers observing the work. The English text had far more vocal clarity, energy and precision, and this flowed over into the physical precision and energy. They were enlivened by the foreign tongue and de-energized when speaking their own. Again and again they reduced both the size and energy of their gestural language when speaking in Romanian, simultaneously losing vocal energy and colour. Why? Why was language operating so differently here? (see Figure 3).

At the end-of-day this was explored in depth through discussions with the cast, who had also observed the enervating effect their own language was having on their work. What they suggested, after considerable debate, was that the effort entailed for them in speaking English held them back from end-gaming or getting into psychological interpretations. Their freedom from habit in the foreign tongue allowed them to experiment more freely, held them more firmly in the present moment, focusing on each other and what they were doing, reacting to external stimuli, rather than thinking and deciding. Why then was this not the case in India or indeed in many other multi-lingual performance situations previously experienced?

\footnotetext{
${ }^{10}$ Universitatea Nationala de Arta Teatrala si Cinematografica, March 18-27, 2013.
} 


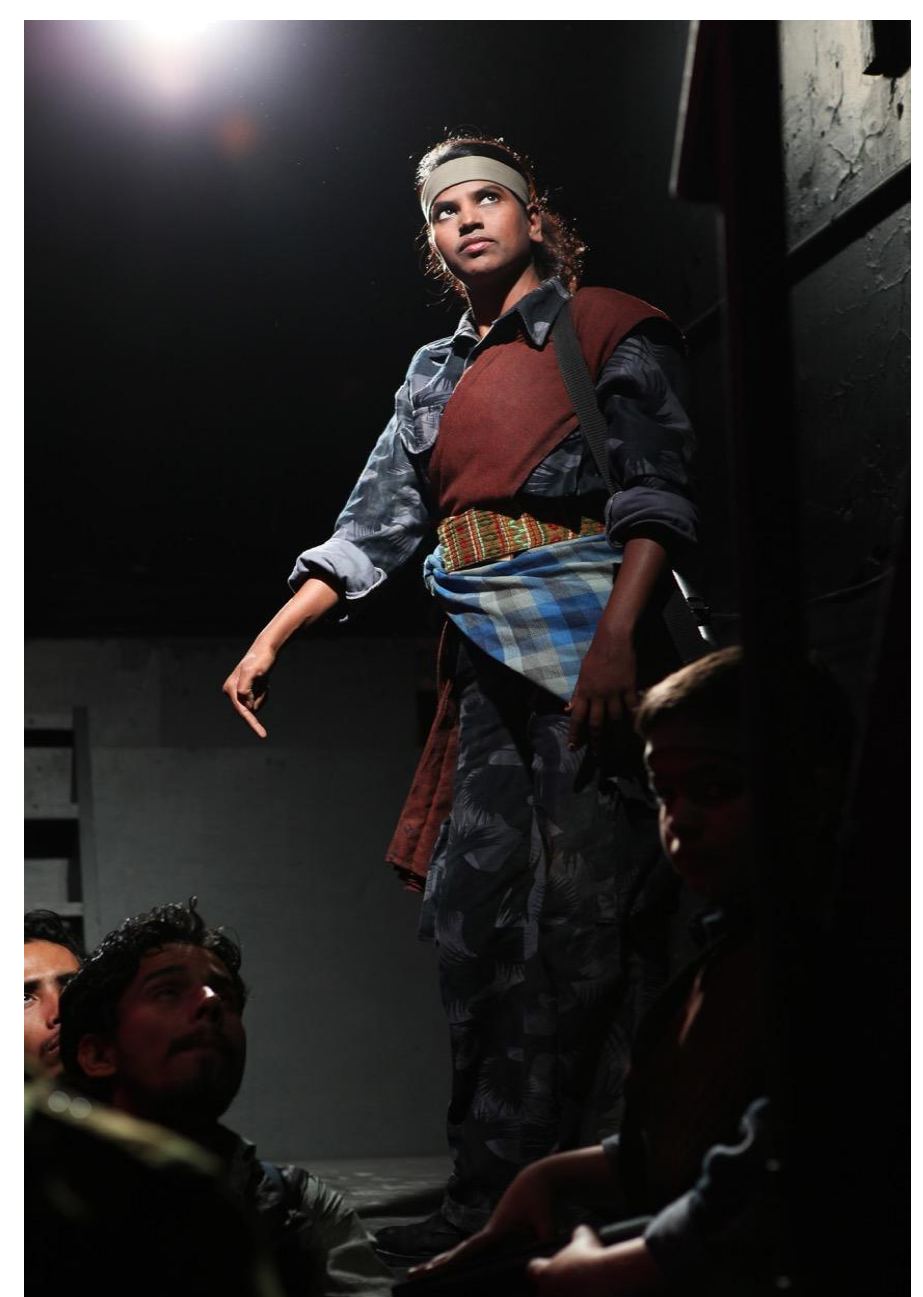

Figure 3. Woman speaking in Tamil, performance of Moira Buffini's Welcome to Thebes, New Delhi, 2012. Photographer: S. Thyagarajan.

\section{The Past Re-examined}

This began a re-examination of multi-lingual situations in my past work, looking for clues to what seemed like a huge anomaly. And in doing this was forced to "see" that past creative work anew. In Shakespeare's King Lear Kent advises the king to look again, to see his daughter's offering through a less familiar, but more appropriate lens: "See better, Lear" (Shakespeare, 1997, p. I.i.158). This laboratory was giving me a fresh lens, enabling me to better understand what had previously been observed, but not truly "seen". As director of Toi Whakaari: NZ Drama School for 14 years I had often had occasion to audition actors for whom English was a second language. Working to elicit stronger work from them, the staff would often invite them to re-work a speech in their mother tongue, and, almost invariably, their work came alive. But did it come alive because they were speaking their first language, or was some other factor in play? I vividly recall some of these moments, as when a Chinese man told a story from his childhood that in English had been overly mannered, but which, in Mandarin, became delicate, connected and beautifully precise, drawing those watching into a different world. Consider the Samoan actors whose native language grounded them, while allowing a playfulness and fluidity missing when they spoke to us in English-why did this happen? I had thought I knew the answer, but now I could not be so sure. 
In 2012 I had conducted the first of these performance laboratories for the International Centre for Voice at Royal Central School for Speech and Drama, London, mixing biographical and extant text. Unlike in Bucharest, where all the actors shared the same mother tongue, in this laboratory of only five participants, the first languages were Korean, English, American English, French and Ewe, one of the languages of Togo in West Africa. The use of mother tongues, as well as providing hugely variant aural textures, brought with them deep-seated personal connections, and vocal ease, which the actors were able to extend into the Gregory text. I noted in my production diary: "The extraordinary connection in personal texts is beautiful... The differences in cultural background among the cast are very rich and this is made tangible in their different languages" (Ruth, 2012) (see Figure 4).

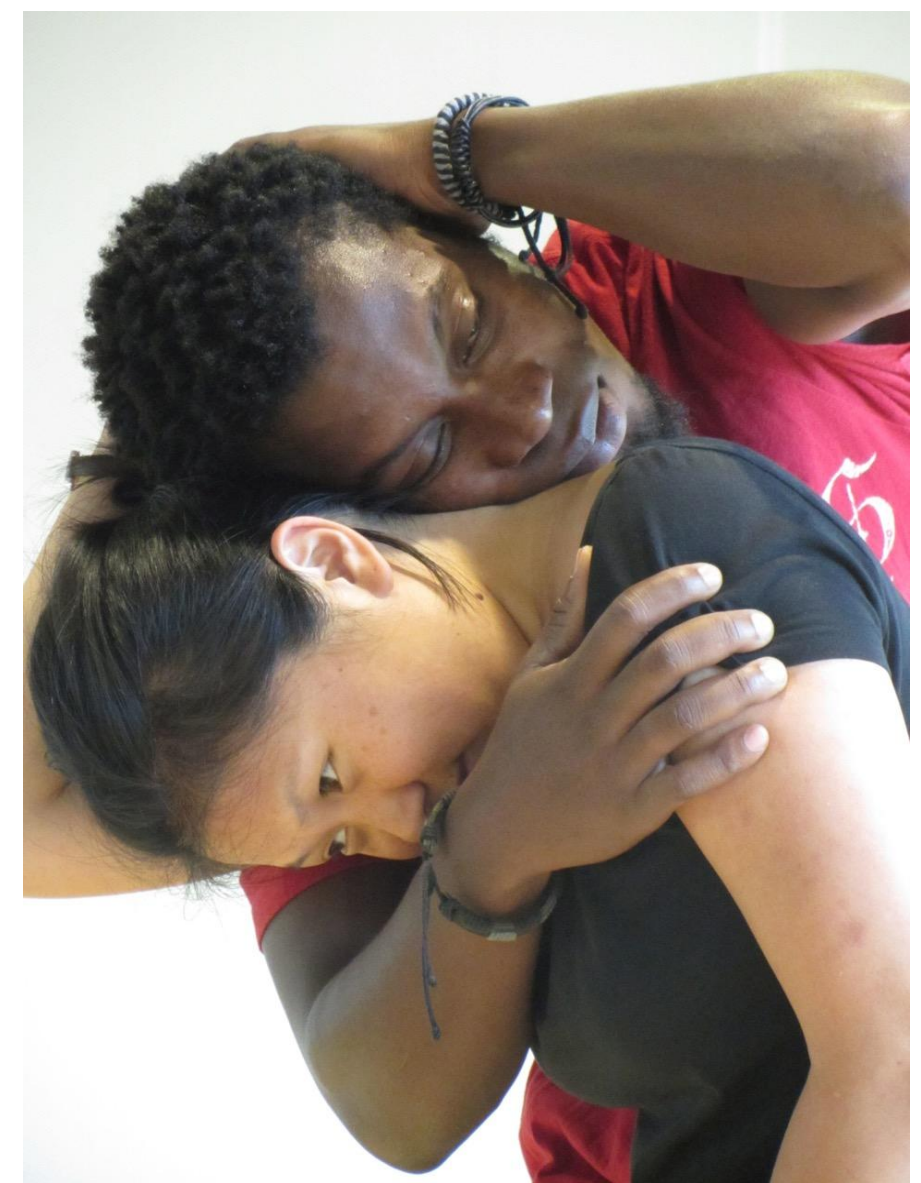

Figure 4. Actors, International Centre for Voice, London, 2012.

Observing the performance at the end of the laboratory, Jane Boston, Director of the International Centre for Voice, wrote:

The principle of telling ones own story seemed to encourage the performers to become accustomed to integrating it with the previously composed text. This process seemed to provide a way whereby the performer realities, along with those provided by the author, could form a bridge between interpretive work, long been part of the British voice training system, psycho-physical work and post dramatic theory. In these ways, enactment could create the voice instead of voice leading the enactment and vocal ease could ensue. ${ }^{11}$

11 Boston, Jane. Emailed response to Bone Songs Laboratory, 12 March, 2013. 
Using their first languages for segments of the work seemed to me an essential part of that ease. And also of the vitality and a certain sense of urgency the actors brought to the relationship with the audience.

Looking back it is clear that another factor was operating in these experiences, one to which I had not paid sufficient attention at the time, that of the difficulty of speaking across a linguistic barrier. The Korean woman speaking her own language to an English-speaking audience, the African speaking Ewe, were both grounded by their own tongue, and at the same time striving to connect across the language barrier in the face of possible misunderstanding or incomprehension. Perhaps it was not (or not only) the fact that these actors were speaking their mother tongues, but that they were speaking them to people who did not understand them that brought the sense of energy? Perhaps the groundedness, the clarity the physical and vocal energy were at least partially a result of needing to use everything in their being to communicate to an audience who would not understand their words? Was it the level of difficulty that was the life-giving force? I considered how powerful the work of the Korean actor was, in both English and Korean. In both cases she had to reach across a huge language barrier, her English being heavily accented and therefore strange to the unhabituated ear. Yet her level of communication was phenomenal and her ease through a huge emotional journey truly remarkable (see Figure 5).

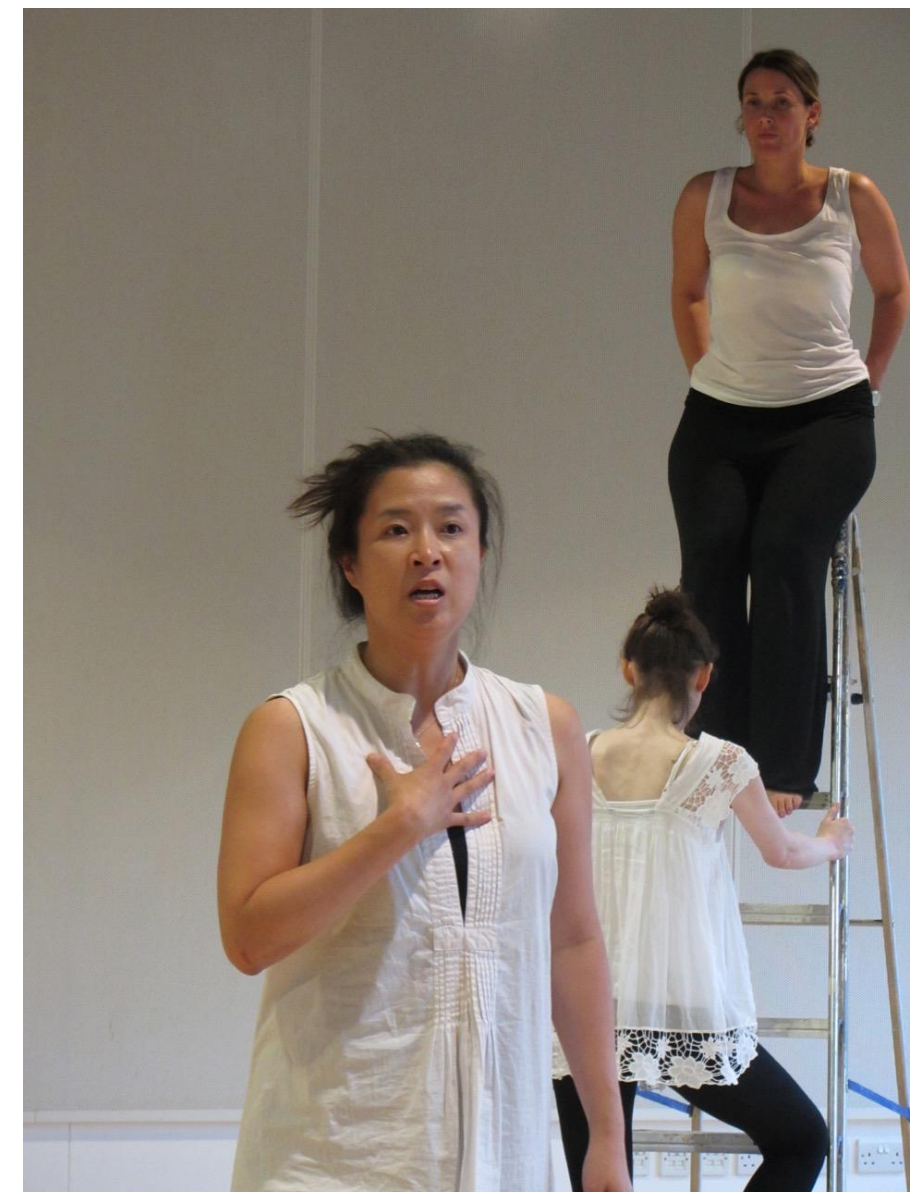

Figure 5. Actors International Centre for Voice, London, 2012.

I have long understood that putting actors under physical stress or giving them almost impossible tasks to perform while speaking their text brings a great sense of life to the work. Indeed, this work with Viewpoints-based choreography is based on this principle. I have also seen the relaxation, the lack of tension 
that comes with these all-consuming tasks, the actors having no surplus energy for self-monitoring and self-criticism, for anxiety about what the audience thinks of them, or what will happen next. The exigencies of the present fully consume them, allowing a vital connection with their audience in that present. I now see that dealing with a foreign tongue or speaking across a language barrier can have a similar releasing effect. This was certainly the case for the actors speaking in English in the laboratory in Bucharest. Filip (2013) remarks: "Very interesting was the balance between expression in English and their own language. In this matter we had the most unexpected results, as they were free and accurate in English, not in their maternal Romanian, which I consider a paradox" (see Figure 6).

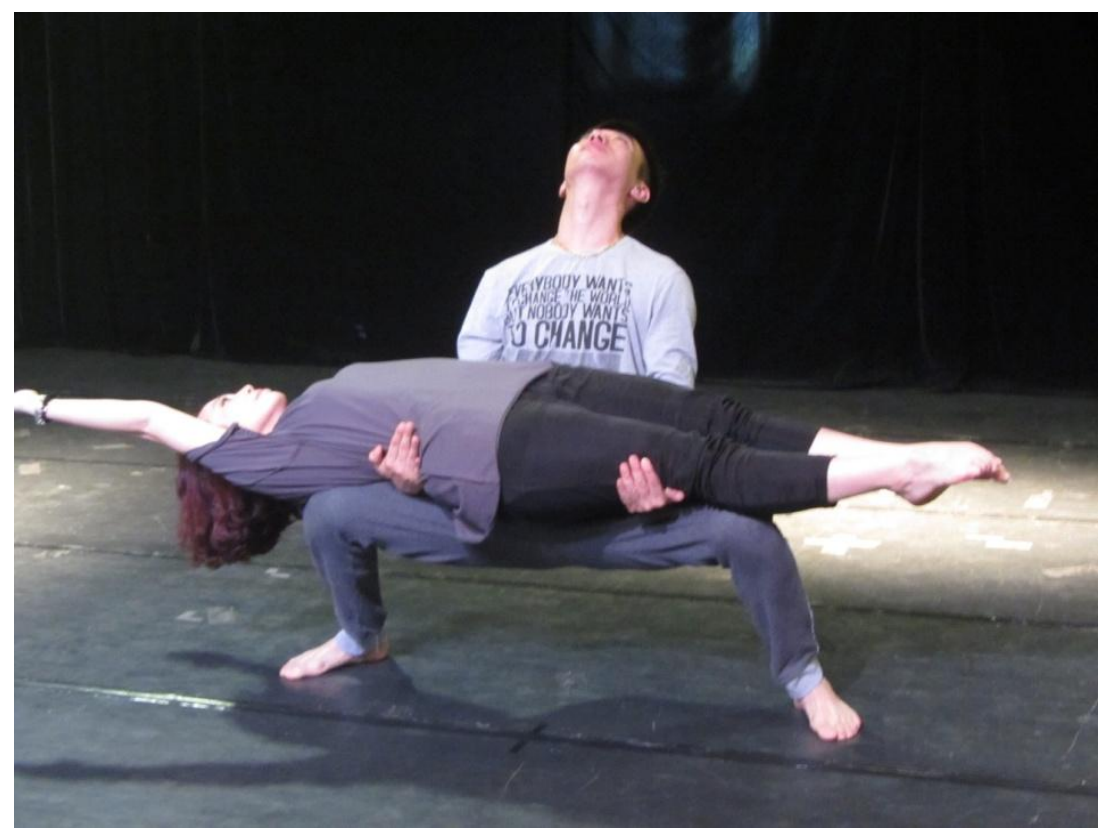

Figure 6. Actor taking another's weight while she speaks the text, Shanghai, 2014.

For these Romanian actors, their own language, spoken to their fellow Romanians, seemed to contain a plethora of pitfalls. Rodenburg (1993) writes:

I think that too many of us hit a barrier when it comes to enjoying words. We have lost the ability to engage with language as a kind of healthy recreation... Words rarely make us giddy with delight the way they do a child. (p. 38)

When the Romanian actors spoke their mother tongue, all the habits, restrictions and vocal codes of their lives and upbringing came into play. In speaking English they had to work hard to find clarity, to remember text in the foreign tongue, and to simultaneously hold onto their complex choreography, and in doing that, some of the relish in the mere sound of the words came back to them. In contrast, in speaking Romanian they began to self-censor, looked self-conscious, reduced the movements they had choreographed to something more realistic, and took themselves into a mode more televisual than theatrical. They were clearly a group highly literate in film and trained in psychological realism and their own tongue led them to revert to a smaller and more contained mode. They lost the freedom and vigour that characterised their work when speaking English. They started playing for effect rather than simply letting the words do the work. Linklater (1992) writes that "Society has taught us that it is wrong to express ourselves freely... All too often the breathing musculature has been dislocated from its instinctual connections..." (p. 5). Speaking their own tongue to people 
who understood it, sadly brought with it this lack of freedom, this hobbling of instinct. When they spoke the foreign tongue, both they and their audiences had to work harder to follow, and this brought with it for the actors the ability to play unselfconsciously. They were not criticizing their own delivery as they spoke, just speaking and moving was task enough. They were, like a sports team at its peak, focusing only on the task, on communicating and watching each other with fierce attention, not judging how they might be received.

\section{The De-energizing Effect of the Familiar}

It is only now, considering the work in hindsight, that it has become clear why this strange de-energizing occurred. We were, of course, working very quickly, since we had only 10 days together. But I now see that I needed to "problematize" their work still further when speaking Romanian, so that this pressure could be taken off them and the release they found in speaking English be replicated. When working with English-speaking actors performing to English-speaking audiences, I am instinctively aware of this, and work to increase the level of difficulty so that the space for self-monitoring is diminished. Here there had been a presumption that turned out to be erroneous. These actors needed to be helped to encounter their own language with a more child-like wonder and I believe that a greater focus on the vocal Viewpoints ${ }^{12}$, where exploration rather than meaning is the focus, would have helped them to do this.

\section{Carrying the New Understanding Forward}

This new understanding of the connection between the struggle to surmount a language difficulty and a greater vitality and urgency in communication was reinforced in the third laboratory conducted in Shanghai in May $2014^{13}$. All of the participants spoke Mandarin as well as a number of other Chinese languages, their individual mother-tongues. Very few had any proficiency in English, so for the most part we worked in Mandarin (myself working through a translator), with a smattering of English phrases. In fact I was hesitant about asking them to attempt any of the work in English, but following the discoveries in Bucharest, it seemed important to explore the effect on the immediacy of the work when they attempted to communicate under that level of difficulty. The complexity was further enhanced by the variety of professional backgrounds within the group. Most had substantial professional careers as directors, Chinese Opera performers, dancers, choreographers, actors, and playwrights, with a small number of MA Directing students joining in. The rich mix of art forms made for fascinating and often surprising work. As before, we mixed biography with the extant text.

Two moments are worth noting. A Chinese Opera performer in his fifties spoke about his grandfather. Telling his own story was an unusual and challenging act for a man used to working in the highly coded world of Chinese Opera. He spoke in a dialect, so, while it was possible for the others to follow him, they had to work a little harder to do so, as did he in the telling. In the performance at the end of the laboratory I noticed the dancer standing close to him as he spoke had tears tricking down her otherwise impassive face. He spoke softly, but the focus on him from the ensemble was beautiful to observe. In the reflection session at the end of the Masterclass he spoke of the sense of liberation he had in doing this work and the lack of the usual anxiety he experienced in performance. His focus on reaching out to others had removed the physical pain to which he had

\footnotetext{
12 The vocal Viewpoints are Pitch, Timbre, Dynamic, Acceleration/Deceleration, Tempo, Silence/Pause, and Repetition. These are typically taught separately to the physical Viewpoints, applied to a piece of text. During the laboratory project for the International Centre for Voice, London 2012, I coined a further vocal Viewpoint - that of "Texture" to describe experiments with smooth and staccato deliveries not quite brought forward by the other titles.

${ }^{13}$ Masterclass Series in Directing: Oceania Focus, Shanghai Theatre Academy, May 2014.
} 
become accustomed when performing and allowed him a more easeful and direct connection to the audience (see Figure 7).

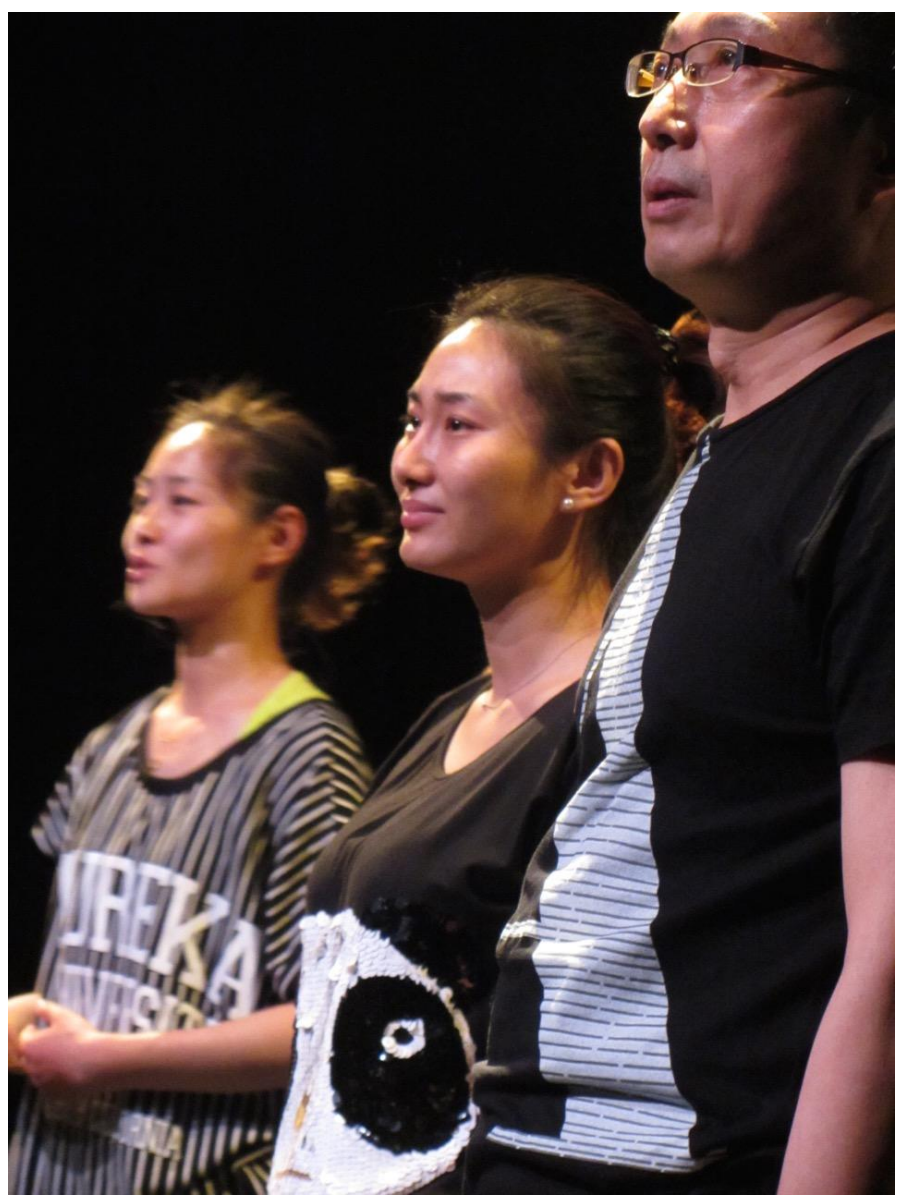

Figure 7. Actor telling the story of his grandmother, Shanghai, 2014.

At another moment a participant was given the phrase "You wanted to come". Originally the phrase was to be spoken by someone with some confidence in speaking English, but when he fell ill an actor for whom it was an enormous challenge took over the line. It is a tiny phrase yet every syllable of it was filled with struggle and urgency as he spoke, his body and voice filled with a yearning to connect, making memorable what might have been an insignificant moment in performance.

\section{Conclusion}

All of which experiences point towards the conclusion that it is the need to communicate through obstacles that essentially brings the sense of life. Native tongue alone is not, and never was, the only key-reaching outward through difficulty is. Bogart (2013) writes:

I have found that many great questions can be answered with a single word: Exactly. These questions are themselves an embodiment of the action of trying to answer them. How can I balance my personal and professional life? Answer: Exactly.

Waking ourselves up, seeing anew, all depend on shaking ourselves out of the habitual and here I discovered a new layer of that awakening. In posing the question: "does performance vitality and connection 
arise from speaking in the mother tongue or from the necessary reaching out to bridge a language barrier?". I have to conclude, with Bogart, "Exactly".

\section{References}

Bogart, A. (2001). A director prepares: Seven essays on art and theatre. London \& New York: Routledge.

Bogart, A. (2013). What's the question?. Retrieved from http://siti.groupsite.com/blog/index.html

Brook, P. (1968). The empty space. London: MacGibbon \& Kee.

Cummings, S. T. (2006). Remaking American Theatre: Charles Mee, Anne Bogart and the SITI Company. Cambridge: University Press.

Goodall, J. (2008). Stage presence. London \& New York: Routledge.

Gregory, A. (2006). Bone songs. New York: Theatre Communications Group.

Lampe, E. (1992). From the Battle to the Gift: The directing of Anne Bogart. The Drama Review, 36(1), T133.

Linklater, K. (1992). Freeing Shakespeare's voice. New York: The Theatre Communications Group.

Rafael, M. (2008). Telling stories: A grand unifying theory of acting techniques. New Hampshire: Smith and Kraus.

Rodenburg, P. (1993). The need for words: Voice and the text. London: Methuen.

Ruth, A. (2012). Production Diary. Bone Songs Laboratory, International Centre for Voice, London.

Salmond, A. (1975). Hui: A study of Māori Ceremonial Gatherings. Auckland: Reed.

Shakespeare, W. (1997). King Lear. In R. A. Foakes (Ed.), The Arden Shakespeare. London: Thomas Nelson and Sons. 